\title{
A Working Common Representation of Group and Organizational Processes
}

\author{
Kenneth D. Mackenzie ${ }^{1,2}$ \\ ${ }^{1}$ School of Business, University of Kansas, KS, USA \\ ${ }^{2}$ EMAC Assessments, LLC, KS, USA \\ Correspondence: Kenneth D. Mackenzie, School of Business, University of Kansas, Lawrence, KS 66045, USA. \\ Tel: 1-785-749-1006. Email: kdmackenzie@sunflower.com
}

\author{
Received: December 12, 2012 Accepted: January 16, 2013 Online Published: March 4, 2013 \\ doi:10.5539/emr.v2n1p1 \\ URL: http://dx.doi.org/10.5539/emr.v2n1p1
}

\begin{abstract}
This article is the second in a series on the science of group and organizational processes. The earlier article made a case for seeking a common representation of group and organizational processes. This article offers a solution by providing a working definition of group and organizational processes and deriving a working representation of them.

Four candidate group and organizational process representations are introduced and evaluated. The first is the MIT process dictionary, the second is knowledge engineering, the third is dynamic simulation, and the fourth is process frameworks. Each has strengths and weaknesses. At this time the process framework view of group and organizational processes has some advantages. Axioms, definitions, and proofs are used to derive the process framework and some of its properties.
\end{abstract}

Keywords: group processes, knowledge engineering, MIT process handbook, organizational design, organizational processes, process, process representation

\section{Introduction}

The preceding article (Mackenzie, 2012) poses a simple question: "What do the group and organizational sciences need most?" The answer argued is to reach agreement on (1) the concept of group and organizational processes (GOPs), and (2) how to represent them. These are prerequisites to more rapid development. This article presents an analysis of four possible group and organizational process (GOP) representations. It ends by the presentation and derivation of a working common GOP representation.

Mackenzie (2012) began with a model of the science of group and organizational processes. Science is defined as a community of interdependent persons who share an interest in and methodological commitment to the evolution of a body of knowledge. This community has four identifiable subcommunities. The first is comprised of the theorists who develop and test substantive theories of GOPs. The second are the tool-makers who develop deployable technologies for studying GOPs. The third subcommunity consists of the engineers who develop the engineering methods to implement substantive theories of group and organizational processes. The fourth subcommunity is comprised of the managers and consultants who apply the engineering methods and deployable technologies. These four subcommunities are interdependent because actions and developments by any of them can potentially, and usually do, affect the others. Mackenzie has four theses: (1) There will be more rapid development in the science of group and organizational processes when the four subcommunities exhibit greater interdependence. More interdependence enhances the likelihood that developments in one subcommunity will spark developments in the others. (2) In order for the science of group and organizational processes to make rapid strides, a common concept of a GOP and a common representation of GOPS is required. A common language enhances communication and a common representation improves the ability to share and compare ideas and results. (3) The progress of the science of group and organizational processes is not commensurate with the variety and scope of its world-wide activities and extensive membership. (4) Having a common GOP representation is a necessary but not sufficient condition for a healthy science of GOPs.

Mackenzie (2012) presents reasons why (a) GOPs are inherently central in the science of group and organizational processes, and why (b) it is reasonable to pursue the basic problem of defining the representation 
of group and organizational processes. Of the ten reasons advanced for developing a common representation of GOPs, the main one is the ontological fact that, because groups and organizations engage in GOPs, any science of group and organizational processes should rest securely on this foundation. Mackenzie (2012) points out some of the challenges and difficulties in achieving a common GOP representation. A three-stage example is provided of a GOP representation of the mundane process of answering a telephone.

There are literally uncountable numbers of group and organizational processes. A common definition of a GOP and agreement on how to represent them would help provide some order and consistency in the study of group and organizational processes. It would also improve the progress of the science of group and organizational processes.

There are candidates for a common GOP representation, some of which are more developed than others. Which of these is preferable? Two questions need to be answered in selecting a GOP representation. The first is the basic feasibility of a proposed GOP representation. The second is that, if it is feasible, does it meet other standards called desiderata? In order to compare, contrast, and synthesize candidate GOP representations, five criteria are advanced to make the first cut of feasibility.

The five criteria for a feasible GOP representation are:

1. Does it contain the property of having "the breath of life"? That is, does it involve people engaged in the actions and procedures of actual groups and organizations, and does it include the subject matter of such groups and organizations?

2. Does it offer an algebraic structure representing GOPs?

3. Does the proposed algebraic structure hold for identified classes of multi-level GOPs?

4. Is the candidate GOP representation realizable? Can it incorporate actual processual information arising out of groups and organizations? Is it capable of defining how the GOP representation can be deployed?

5. Is the GOP representation falsifiable? Does there exist some means by which claims made in the name of this GOP representation can be demonstrated as inconsistent with some data?

The next question is that, given two or more feasible candidate GOP representations, how does one decide which one is preferred? Because adherents of a candidate GOP representation are likely to be partisan, their bases of preferences may be clarified by applying additional desiderata. Rival feasible GOP representations can be compared and contrasted by applying these desiderata. Mackenzie (2012) advances ten desiderata. These are: (1) Are its definitions and axioms explicitly articulated?; (2) Is the proposed analytical framework implementable?; (3) Can its adherents demonstrate how it can incorporate actual GOP information?; (4) Is it useful for multiple purposes and applications?; (5) Does it have definable limitations?; (6) Does it allow for linking with other GOPs (both vertically and horizontally)?; (7) Does it distinguish and separate the GOP itself from possible evaluations of it?; (8) Is it testable?; (9) Does it have face validity?; and (10) Does it offer value to the advancement of the science of group and organizational processes?

These five criteria of feasibility and ten desiderata are provisional. Further advances will undoubtedly result in additions, modifications, and even deletions from these lists. However, they serve as a starting place for the discussion.

This article begins by reviewing four candidate GOPs. These include the MIT process handbook (Malone, et al., 2003), the knowledge representation ideas and techniques contained in Sowa (2000), the dynamic systems modeling of Melcher (2012), and the process framework models of Mackenzie (2000a, 2004a). Other potential GOP representations are excluded because they are not sufficiently evolved to meet the five feasibility criteria. Their exclusion does not reflect any conclusions regarding their scientific merit. It is also likely that some are not included because of the lack of awareness of this author.

The intuitive notion of a group and organizational process is that GOPs refer to a time-dependent sequence of interrelated events and considerations. Basically, a GOP process describes how group and organizational behaviors occur. A group process is a GOP occurring within a group or between groups. Group processes include both task (how the work occurs) and non-task processes such as socializing, bonding, motivating, etc. An organizational process is a GOP occurring within or among organizations. There is no clear-cut distinction between group and organizational processes. However, the distinction is made because some studies concern behaviors within a group and others, those of an organization.

\section{The Malone, Crowston, and Hermann GOP Representation}

\subsection{Introduction}

Probably the most comprehensive system for developing a science of group and organizational processes is the 
work by those in the MIT Center for Coordination Science. This innovative work is summarized in Organizing Business Knowledge: The MIT Process Handbook (T. W. Malone, et al, 2003). Their primary goal "is to build computer systems that help people design or carry out processes" (p. 24). Their most visible product "is a set of software tools for storing and manipulating process descriptions" (p. 25). They provide "a high level framework of a small number of very generic activities and then classify all other activities as specializations of these high-level activities" (p. 29). This taxonomy consists of very general activities that include those that create, modify, use, move, preserve, destroy, manage, combine, separate, and decide. These general activities can be subdivided into component subspecializations. For example, the general activity of "move" is divided into transfer, give, get, and exchange. The subspecialization of "get" divides into "get what?" and "get how?" "Get what?" divides into "get information" and "get physical items." From this foundation, and by working with companies, consultants, and researchers, they created a system of over 5,000 tasks.

The MIT Handbook is a good example of using the model of science presented in Mackenzie (2012, figure 1). The authors start with a substantive theory of group and organizational coordination processes. They use and develop deployable tools in the form of software. They create an engineering to convert these tools and a theory of coordination to provide a deployable system. They involve managers and consultants to update, expand, and improve their process dictionary. They foster interactions among these subcommunities by providing guidance, publications, workshops, and user-friendly software tools.

A question is whether or not the MIT Process Handbook is a GOP representation. It certainly is feasible. It meets the five criteria proposed in Mackenzie (2012): it incorporates (1) the breath of life; (2) it offers an implied common algebraic structure; (3) this algebraic structure holds for specific classes of multi-level GOPs; (4) it is realizable, and (5) it is falsifiable. Users are asked to provide corrections and improvements. The next question is whether or not it is a common GOP representation.

The answer is probably no. The main problems start with its concept of a process. As will be shown, its base substantive theory is a defective and deficient concept of coordination; its range of group and organizational processes is restricted to a useful but narrow class of task processes; it neglects the roles of structure, human abilities, and emotion in organizations; and it is difficult to see how it can be used to state and test substantive theories of group and organizational processes beyond the scope of its origins.

The MIT Process Handbook, however, is a major accomplishment. In criticizing it as a common GOP representation, I'm reminded of the joke about the poker-playing dog. The dog could shuffle the deck, handle different games of poker with aplomb, and play with the best poker players at the table. The problem with the dog is that whenever it had a particularly good hand, it would wag its tail. That "tell" limited the dog's effectiveness. The MIT Process Handbook's "tell" is its theoretical basis.

\subsection{Definition of a Process of Malone, et al}

Crowston (2003, p. 180), defines a process as: "a sequence of events, focusing specifically on events as activities performed by individuals or groups." Earlier, Crowston used the definition by Boudreau and Rubey (1999) as: "an interrelated sequence of events that occur over time leading to an organizational outcome of interest," (Crowston, 2003, p. 177). The emphasis in the Malone, et al (2003) book is on those business processes that lead to some practical outcome. Process is taken as an undefined but generally understood concept and is not defined until Crowston does it on pages 177 and 180. Later (December 13, 2011), in a personal communication with the author, he affirms the definition on page 180. This definition is limited to business processes that yield useful or interesting outcomes. It does not, for example, deal with the myriad of group and organizational processes such as leadership, policy formulation, structural change, organizational development, and social psychological processes. Thus, on its surface, definition of a process in Malone, et al, 2003 is not general enough to establish a foundation capable of handling the wider range of classes of known group and organizational processes. But this is a self-imposed limitation that can be relaxed by careful modifications.

\subsection{The Central Role of Coordination in the MIT Process Handbook}

The key substantive theory in the MIT Process Handbook is its authors' concept of coordination. Their concept is a more modern form of the earlier work by Thompson (1967). They define coordination as "the managing of dependence" (Malone, et al., 2003, p. 19). This definition is problematic because coordination is a subset of the various processes involved in managing. It is as logical to define managing as the coordination of dependence. Their definition of coordination seems circular. The next question is the notion of dependencies, which is a restatement of the idea of interrelated processes. Dependency is a one-way type of interrelationship. Why limit the theory to dependence? Interdependence is two-way and dependence is a special case. Thus, their definition of coordination is confusing, limited, and possibly tautological. Their definitions of a process and of coordination 
constrain the reach of their work. A common GOP representation must be based on a more general concept of GOPs and interdependencies.

A more comprehensive definition of GOPs would open up wider vistas for conceptualizing group and organizational interdependence. The Malone, et al, concept of dependency consists of these basic types: fit, flow, and sharing. But this leaves out people, how they are structured in a group or organization, and how these processes should be distributed within a group or organization. For example, an important set of considerations in organizations are where the decision should be made to perform a process, who should do it, the scope of the application of the process to the rest of the organization, and the locus of the rights reserved to change it. Are there classes of decisions reserved only for senior management, such as developing strategic plans, or can any clerk make these decisions? Are there classes of processes that the same senior executives ought not to routinely engage in, such as mailing packages? Do the decisions apply to the entire organization or just to a special unit? What is the review process to ensure the proper direction, control, coordination, and execution of a business process? These issues are recognized in Malone and Crowston (1994), but are not explicitly incorporated into their GOP technology.

In contrast, the task interdependence by Mackenzie (2004a) proposes a double hierarchy of task interdependence. There are three levels to the process frameworks: (a) planning, which is strategic as in defining and ensuring the development and implementation of strategic direction, and operational planning involved in changing tasks, structures, and allocation of resources. Then there are (b) the tasks involved with directing, controlling, and coordinating task performance. Directing includes deciding what to do, seeing to it that the tasks are completed, and ensuring that task resources and their characteristics-in-use are available and used. Controlling means ensuring that the execution-level tasks are completed properly. Coordinating means the managing of the many interdependencies. Lastly, the lowest level consists of (c) the execution tasks that are performed routinely.

Except for some coordination and execution tasks, the other types of process laws are not adequately developed and represented by the Malone, et al, system. However, Malone, et al, are explicit about the second hierarchy of task processes of aggregation from higher level general tasks to lower level very specific performance tasks. Malone, et al, are vague about linkages between the two hierarchies. In contrast, Mackenzie combines two hierarchies into an organizational logic which has been extensively used to describe complex skeins of interdependencies, and to generate reports such as position descriptions and organizational charts (cf. Mackenzie, 1986a).

A matrix, called the organizational responsibility group chart (ORG chart), can be used to exhibit linkages among the engaged actors and the many tasks. The ORG chart depicts the engaged actors as rows and the tasks as columns. The matrix's entries describe the actor's specific involvement with each task. These include planning, supervising, performing, and "working with." The ORG chart is useful because its rows define position descriptions and the columns define the chain of command for every task. Thus, the tasks and structural interdependencies are analytically defined and controllable. Reorganizations, for example, involve the tasks of redefining the rows, the columns, and the entries.

Empirical research based on the many organizational design projects by the author also shows that the distribution by type of task process laws exhibit stable patterns (cf. Mackenzie, 1997a, b; Mackenzie \& Benoit, 1997). These empirical regularities suggest even more interdependencies among the tasks.

Moreover, Mackenzie (2001b) in an article entitled, "The Organization of Organizations," argues that the fundamental property of an organization is interdependence. He proposes a general model of organizational interdependencies which includes both high level systemic and lower level operational interdependence. The models of Malone, et al, their definitions of a process and coordination, and their dependence on computer software restricts them to lower levels of operational interdependence.

These issues yield a different concept of management. The concept of management in Malone, et al, is not explicitly defined but it seems consistent with that proposed by Daft (2000, p. 749$)$ in which management is defined as "the attainment of organizational goals in an effective and efficient manner through planning, organizing, leading, and controlling the organizational resources." In contrast, Mackenzie (1991) defines management as "the on-going effort to achieve the organization's strategic direction in the presence of changing conditions through the processes of:

(a) Planning, directing, controlling, and coordinating organizational interdependence, and

(b) Proactively searching for, removing, and preventing process maladaptations." (pp. 184-185). 
In this view, the purpose of management is to achieve the strategic direction. The desiderata are productivity, adaptability, efficient adaptability, and dynamic congruency. The main management processes are (a) planning, directing, controlling, and coordinating, and (b) proactively searching for, removing, and preventing process maladaptations. Managers manage organizational interdependence and not just resources. Managing is seen as a verb as it is on-going, never ceasing. It takes the environment into account as it changes. Control is a verb, not a noun. Managers are both at the top and deployed throughout the organization; technology is vital and built into the concept of organizational interdependence; work is included in the notion of organizational interdependence; and the main duty is to manage the processes producing the results. While Malone, et al, are not very explicit about management, there are many similarities with Mackenzie. They differ on the inclusion of GOPs that include the role of environments, processes of managing, and the processes of planning. These differences stem from their view of processes and interdependence.

In summary, the Malone, et al, MIT Process Handbook is a remarkable achievement in evolving a representation of group and organizational processes. It is superior to that of Mackenzie in its creative and adaptive use of computer technology. But, because of its original notions of processes and dependence, it is not yet a viable candidate for a common GOP representation.

\section{Other Possible GOP Representations}

\subsection{John Sowa's Knowledge Representation Tools}

Strictly speaking, John Sowa's 2000 book, Knowledge Representation: Logical, Philosophical, and Computational Foundation, is not meant to be a text about the science of group and organizational processes. It is, however, included in this review because it offers a valuable compendium and discussion of potentially useful tools. This book is a graduate student textbook of knowledge-based analysis and design. Knowledge Representation includes a chapter on discrete and continuous processes. The discussion about the tools and their limitations is lively and useful. This book is filled with useful methods for handling processual information, such as logic (predicate calculus and conceptual graphs), rules, frames, semantic networks, object-oriented languages, Prolog, Java, SQL, Petri nets, and the knowledge interchange format. He introduces underlying origins of methods and their philosophical controversies. This interdisciplinary work includes helpful doses of philosophy, history, and linguistics.

There are serious philosophical arguments against embracing knowledge engineering too closely. The main one is the futility of representing knowledge independently of the person knowing the knowledge. Disembodied knowledge is an oxymoron. For example, two people can read Sowa's book and not have the same knowledge when they finish it. Owning the book does not infuse knowledge into the owner. Separating knowledge from its knower is, in general, a fallacy, and a huge problem for knowledge engineering.

It is useful to remember that current efforts to represent knowledge grew out of work in artificial intelligence (AI), which Sowa defines as "the science of designing computer systems to perform tasks that would normally require human intelligence." This work has been useful in tasks requiring innate knowledge or knowledge learned by repetition, and activities that can be learned by rules. It has had limited success in more complex problems which have formal rules. But, it fails in tasks requiring common sense and genuine expertise. The philosopher H. L. Dreyfus (1993) shows why this is the case. However, hybrid research combining machine computation and human abilities offers hope.

Sowa presents knowledge representation as a multi-disciplinary subject that applies ideas and methods from logic, ontology, and computation. Logic provides the formal structure and rules of inference. He describes ontology as defining "the knowing of things that exist in the application domain" (p. xi). "Computation supports the application that distinguishes knowledge representation from pure philosophy" (p. xii). This trio of ideas and methods is reflected in the subtitle of his book.

The AI origins are evident in Sowa's notion of ontology. For example, Sowa declares that "the subject of ontology is the studying of the categories of things that exist or may exist in some domain. The product of such a study, called by him an ontology, is a catalog of the types of things that are assumed to exist in a domain of interest from the perspective of the person who uses a language for the purposes of talking about the domain" (p. 492). This is a limiting rendering of the philosophy of ontology, which is more broadly interested in understanding reality, and is considered a verb rather than a noun. Reducing the philosophy of ontology to lists may be useful in computer design, but it leaves out the human as an engaged agent who has extensive background knowledge (cf. Taylor, 1993).

Sowa is well aware of the philosophical and practical limitations of knowledge representation. He offers an 
evocative chapter entitled, "Knowledge Soup" with this quotation from Alfred North Whitehead (1937):

Human knowledge is a process of approximation. In the focus of experience, there is comparative clarity. But the discrimination of this clarity leads into the penumbral background. There are always questions left over. The problem is to discriminate exactly what we know vaguely (Sowa, 2000, p. 348).

Sowa introduces the notion of a knowledge soup to reflect that some knowledge in people's heads may be expressed in propositions, but much of it is tacit in the form of habits, vague intuition, and gut feelings that are never verbalized or visualized. "This knowledge is far too complex and disorganized to be called a knowledge base. Its fluid, heterogeneous, ever changing, and often inconsistent nature could be better characterized as "knowledge soup" (Sowa, 2000, p. 348).

The existence of this knowledge soup creates unsolved (and possibly unsolvable) problems in the type of knowledge representation needed for computation and artificial intelligence programs: language becomes a tool for discriminating and creating knowledge out of our knowledge soups. In the case of group and organizational processes, the pursuit of a common GOP representation can provide such a type of language for these processes. It is hoped that the inventiveness and creativity of those seeking to represent human knowledge will, eventually, yield ever more profound and useful methods for representing group and organizational processes.

The fact that most GOPs are specific in their context and purpose sidesteps some of the intractable issues of logic and language because their grounded specificity eschews the quixotic, chimerical pursuit of universality. The more modest effort to find a common GOP representation of actual group and organizational processes takes advantage of their limited purposes, specific contexts, and human behavior in groups and organizations.

However, if one steps back from the philosophical problems of Sowa's knowledge representation, one can see many methods and ideas that could inform processual research. His interdisciplinary trio of logic, philosophy, and computation can be applied to GOPs. The philosophy is helpful in defining the GOP and how one describes it. The logic shows how to combine the elements of the GOP formulation into a coherent whole. Computation informs one how to apply the logic and reveals consequences. These three interdependent ways of thinking are germane to the study of GOPs. Sowa provides example after example of how to apply this trio of ideas and techniques.

As it stands, Sowa's work cannot be a feasible representation of group and organizational processes. It is not meant to be one. It contains a useful and powerful set of tools, whose use can stimulate the science of group and organizational processes. The work by this subcommunity of tool developers ought to be embraced by others in the science of group and organizational processes.

\subsection{Melcher's Dynamic Simulation}

Engineering is the vital link between theory and tool development because engineers are needed to figure out how to implement new theory and applicable tools. Although the lack of engineering in the science of group and organizational processes is a major weakness, there are a few who have worked in this area for years. Organizational design, organizational development, and human resource management are bright spots. But, for the most part, those who attempt to develop engineering for GOPs labor in relative obscurity.

One notable example of a long-term engineering effort is that of Arlyn Melcher. Melcher has worked for decades to evolve methods for how to engineer systems dynamics models to study certain group and organizational processes. Melcher's 1976 monograph, Organizational Structure and Process: A Systems Approach, lays the conceptual foundations for this body of work. His approach begins by investigating a phenomenon in order to provide a grounded theory for it. This provides a clear context while improving an investigator's intuitive understanding of the phenomenon. The goal is to understand the system dynamics of the many possible interdependencies that could influence the behavior of the system. Next, the researcher proposes and investigates the effects of a series of underlying processes and their interdependencies. Then, after an exhaustive investigation of the linkages, the researcher iterates simulations of the postulated dynamics to arrive at a plausible explanation of the phenomenon.

This body of work is relatively obscure, in part, because it is difficult to publish this line of research in academic journals. One exception is the systems dynamics results by Roger Hall, in which he investigates the dynamics of the demise of the magazine, The Saturday Evening Post (1976) and the dynamics of a Canadian curling association (1984). Although Roger Hall is not directly linked to Melcher and his colleagues, his articles ably illustrate the potential of the systems approach for the study of group and organizational processes.

Melcher's work depends upon creating a system of typologies for identifying the causal processes. For example, Acar, et al (1989) developed a typology for competitive strategies of firms. Milestones in the evolution of 
Melcher's engineering are Melcher (1976), Melcher and Melcher (1980) and Melcher, et al, (2002). The culmination is Formulating a Research Questions: Considerations and Guidelines (Melcher, 2012). Melcher has either chaired or co-chaired thirty dissertations which involve his approach.

The heart of his approach is to carefully define the independent variables, the moderating variables, and the dependent variables that are deemed relevant to the research question. The strength of this work is to capture the system dynamics of how these interdependencies play out over time. The result is an understanding of a phenomenon that is rarely found in the usual variance modeling methods. A weakness is the lack of cumulation of the underlying science of these phenomena. As this body of GOP research lacks ready acceptance in the academic disciplines (as represented by publications in academic journals), it tends to lie outside the publishing mainstreams. The lack of fertile interdependencies with other lines of research limits its reach. This is unfortunate for the science of group and organizational processes because Melcher's work contributes important insights into the dynamics of GOPs.

From the viewpoint of evolving a common representation of GOPs, Melcher's work has the problem that his notion of a GOP is undeveloped. He defines a process as "the activities and functions that actually occur" (Melcher, 2012, p. 76) and a process variable is "defined in terms of degree an activity is carried out" (Melcher, 2012, p. 76). In this work, processes become encapsulated into process variables, and the analysis is not so much about the underlying GOPs but about how the dynamic interdependencies of the process variables play out in the successive iterations of the system's dynamics. Thus, given the criteria for feasibility for a GOP representation, his models are not yet feasible. They certainly have the "breath of life," but they lack a common algebraic structure for the representation of GOPs. The realizability of the underlying GOPs is problematic and the criterion of falsifiability is difficult to assess given the many possible outcomes and nuances of an iteration of simulations.

It is safe to conclude that Melcher's system dynamics does not yet provide a common GOP representation. However, it is also possible that he is working on a new phylum of GOPs, which will force revisions in the concept of a GOP and how to represent them.

\section{The Process Framework as a Common GOP Representation}

\subsection{Introduction}

The process framework representation of group and organizational processes has been under development since at least 1964 (cf. Mackenzie, 1976a, b). It has been used in an extensive range of applications involving the statement and testing of substantive theories of group and organizational processes over a long period of actual use in organizational design (Mackenzie, 1986a, 1991, 2011).

The 1976 books reported on more than a decade of studying GOPs involved in the functioning and structural changes in emergent little laboratory groups. GOPs were used to explain and predict how tasks and incentives influence how these five-person laboratory groups organized themselves to solve problems. It also contained a GOP for the formulation of interpersonal hostility.

Lippitt and Mackenzie (1976) used a process framework of a GOP to explain how university officials handle inconsistencies between their authority and their tasks. The process framework predicts the choices of actual academic officers about structural solutions to such problems. They were presented with scenarios and were asked to choose a solution among a set of seven alternatives. The process framework is accurate. It is also very stable. In fact, for over two decades, students in an MBA organizational behavior class were offered an A in the course if they could construct and defend a counterexample. The process framework has eleven binary considerations and seven outcomes. This yields a potential of 2,047 paths from the first consideration to the outcomes. But, because the process framework makes use of the relationships between the considerations and the outcomes, the actual process framework has only 28 paths, a reduction of $98.6 \%$. Mackenzie (1986b) extended the approach to handle informal as well as formal decision-making groups. This led further to the discovery of virtual organizations (Mackenzie, 1986b and Mackenzie and Scott, 2001) and virtual processes (Mackenzie, 2000d) and to a discussion of non-governmental organizations (Mackenzie, 2001a).

Process frameworks have been used for a variety of substantive group and organizational theories. In the study of leadership, there is an emergent leadership experiment (Mackenzie \& Bello, 1981), a theory of organizational leadership (Mackenzie, 2006a, Mackenzie \& Barnes, 2007; Mackenzie \& Pate, 2009) and a survey method for evaluating organizational leadership (Mackenzie, 2011). The process approach is the basis for a theory of the organizational hologram (Mackenzie, 1991), which is a theory of how efficiently adaptable organizations operate. It is also the basis for a theory of organizational interdependence (Mackenzie, 2001b), to define a model of organizational goals (Mackenzie, 1998b) and to develop and test a model and data for a theory of 
organizational-level learning (Mackenzie, 1994). It formulated a theory of organizational power (Mackenzie, 1986b). It has been used to state a theory of organizational risk (Mackenzie, 1998a).

The process framework approach has been used in developing models for quality assurance (Mackenzie, et al, 1994 and Barnes, 1996. It has been used to analyze political events such as the Gore/Bush Florida recount (Marker, 2002) and to formulate a theory of federalism and apply it to an analysis of the efforts by a U.S. President, F. D. Roosevelt, to pack the U.S. Supreme Court in 1937 (Mackenzie, 2010).

The process framework has been involved in a number of methodological studies, ranging from the research process of converting data to their implications (Mackenzie, et al, 2000) and multi-level studies (Mackenzie, 2004a, b, c). It has been used to develop methods of testing processual models (Mackenzie, 2006b); the use of strong inference instead of statistical models to test processual models (Mackenzie and Rahim, 2003 and Mackenzie, 2006b), and a general critique of variance models (Mackenzie, 2007). Process frameworks provide a base for new types of survey methods (cf. Mackenzie, 2000b, c, and 2011).

Process frameworks are the foundation of the organizational audit and analysis technology for organizational design (Mackenzie, 1986a). Process frameworks can be converted into ordinary mathematical functions (Mackenzie, 2009). Thus, there is evidence of the utility of process frameworks for many purposes, such as problem-solving, stating and testing substantive theories for group and organizational processes, application to organizational design and quality assurance, and related methodologies.

The generality of process frameworks is still questionable because its applications have barely scratched the surface of the immense variety of group and organizational processes. For example, this line of process research does not include analyses of sensemaking (cf. Giola \& Chittipeddi, 1991, Maitlis \& Lawrence, 2003; Weick, 1995. Further, it also has not studied organizational identity phenomena (cf. Giola, Schultz, \& Corley, 2000; Polkinghorne, 1988). It also has not been deployed to study narrative research (cf. Pentland, 1995, 2003). Consequently, the range of topics studied by the author is not exhaustive of the possible types of GOP research and should not be considered general.

As the process framework GOP representation has evolved, it has been subjected to numerous challenges and revisions. Along the way, attempts were made to develop a suitable mathematical framework based on an integrated set of definitions, axioms, propositions, and theorems. This paper is the first to derive $\mathbf{Y}=\mathbf{F}(\mathbf{C})$ from a base set of six ontological axioms. The hope is that this will make the structure of the argument so clear that it will invite challenges; to explain the essence of a GOP as it is currently understood by the author; and to encourage others to improve or reject it.

\subsection{Some Basic Notions for GOPs}

In the process framework GOP representation, a GOP process is defined as a time-dependent sequence of events or considerations governed by a GOP framework, $\mathbf{Y}=\mathbf{F}(\mathbf{C})$. A GOP framework is a graph (or a network) linking the considerations to each other and to the outcomes of a process.

A key concept in a GOP is that of a Processual Agent (PA), which is any internal agent that can affect a GOP. PAs are usually individuals but they may also be teams, virtual teams, committees, units, and even other organizations. PAs need not always be human but every GOP must involve humans. For example, signals and commands from a control system may "act as if" they are Processual Agents, especially when compliance is enforced by others. External events outside the control of the group or organization, such as natural disasters, labor strikes to a supplier, accidents preventing deliveries, etc., are not considered PAs.

Processual Agents in process frameworks are assumed to be engaged Processual Agents. Following C. Taylor's essay (Taylor, 1993) entitled, "Engaged Agency and Background," a PA is much more than a "rational" information processor. An engaged PA is not some abstract disembodied calculating machine. To the contrary, a PA is actively engaged within his place. The PA is "embedded in a culture, a form of life, a world of involvements, ultimately to understand the agent as embodied" (Taylor, 1993, p. 318). This embodiment shapes the PA's perception who is "world shaped" which means "embodiment in the sense of experiencing or 'living' the world is essentially that of an agent with this kind of body. It is an agent who acts to maintain equilibrium upright, who can deal with things close up immediately and has to move to get things farther away, who can grasp certain kinds of things easily and other not, can remove certain obstacles and others not, can move to make a scene more perspicuous, and so on" (Taylor, 1993, 318-319). A PA is not some abstract disengaged thinker. A PA is not simply a calculator gathering bits of information and then processing them in order to decide what to do and then acting to fulfill goals through some sort of means-ends calculus. A PA is not neutral, accepting "data" as if it must be correct. 
Knowledge engineering attempts to ontologize this disengaged agent by assuming that a PA thinks the way that is consistent with "rational" calculus would dictate. Not quite: the engaged agent shapes his world. "Engaged agency is that agency whose experience is made intelligible only by being placed in the context of the kind of agency it is" (Taylor, 1993, p. 325). The engaged agent's background helps make his world intelligible. This experience and background gives the PA an implicit understanding "of what it is to act, to get around the world, the way we do" (Taylor, 1993, p. 327). "Engaged agents are creatures with a background sense of things" (Taylor, 1993, p. 328).

The notion that PAs in process frameworks are engaged agents means that the process framework the PA attends to is defined with respect to the PA. The PA is involved in defining the context, the considerations, the process framework, and the outcomes. The PA is, in the words of M. Wooldridge and N. Jennings (1995), reactive in that the PA perceives aspects of the environment and reacts appropriately. The PA is also proactive because the PA can take initiative in performing goal-directed actions. Whenever a researcher develops a process framework, the researcher should have PAs review it in order to "get it right."

In what follows, the PA is assumed to be an engaged agent. The present version of process frameworks could be enriched by introducing axioms of the decision processes of the PAs. Such axioms are not introduced here, but introducing them will expand the properties of GOPs. For now, it suffices merely to introduce the first ontological axiom.

The effecting of a process requires an action by a Processual Agent, which is the first ontological axiom:

\section{Axiom 1. A GOP involves one or more Processual Agents.}

Processual agents are engaged agents. They are reactive and proactive. They are not objects or mere resources.

One of the essential properties of GOPs is that they involve both the Processual Agents and what they do. This involvement takes the form of linking. There are no GOP behaviors without linking. This is the next topic.

\subsection{Linking GOPs Together}

GOPs are typically represented in graphs or networks containing boxes and links connecting the boxes. Each box represents one of the steps in one of the sequences of considerations in the process. Many times the lines and/or arrows linking them start off by being vague. These links are important to achieving a GOP representation and are developed as the interdependencies become understood and defined as the analysis proceeds. These links include that which is being linked and the links themselves.

Every GOP contains these process elements: (1) events, (2) considerations or steps, and (3) subprocesses. Let $\mathbf{E}_{\mathrm{i}}$ and $\mathbf{E}_{\mathrm{j}}$ represent a pair of GOP elements. $\mathbf{E}_{\mathrm{i}}$ is the predecessor of $\mathbf{E}_{\mathrm{j}}$ if it "precedes" it, as indicated by the link $\mathbf{E}_{\mathrm{i}}$ $\rightarrow \mathbf{E}_{j}$, and $\mathbf{E}_{\mathrm{j}}$ is the successor to $\mathbf{E}_{\mathrm{i}}$ in this link. Note that if $\mathbf{E}_{\mathrm{i}}$ is the predecessor of $\mathbf{E}_{\mathrm{j}}$, then $\mathbf{E}_{\mathrm{i}}$ produces outputs to create the event that triggers $\mathbf{E}_{j}$. The predecessor can be interpreted as preceding, triggering, or causing $\mathbf{E}_{j}$. Any process element can be preceded and succeeded by any other process element.

Linking GOP elements involves more than merely drawing a line between a pair of boxes. In fact, for task processes, there are specific requirements to effect the linking of a pair of GOP elements (Mackenzie 2000a) specifically, two task process elements need to have the property of being "in-common."

An integrating GOP is one that creates an in-common set of processes. GOPs $\mathbf{P}_{\mathrm{i}}$ and $\mathbf{P}_{\mathrm{j}}$ are directly integrable if: (a) there exists an integrating process at the same level that creates in-commonness, or (b) one could be developed. Usually, when conducting an organizational design project, it is necessary to create in-commonness across locations, product lines, customers, suppliers, and information technologies, etc., with different managers, process resources and their characteristics-in-use. This is especially vital when units are being reorganized. One method for creating in-commonness is to redesign the GOPs and to create processes to plan, and to direct, control, and coordinate various execution task processes. It is also necessary to assign PAs to the processes in order to maintain compatibility.

We are now in a position to state Axiom 2.

Axiom 2. A GOP involves two or more linked process elements.

This leads directly to the first GOP property:

GOP Property 1. A GOP involves one or more processual agents and two or more linked process elements.

Argument: This follows directly from Axioms 1 and 2.

GOP Property 1, while analytically trivial, is helpful when extracting GOPs out of a specific context. For example, any effort to define a GOP must involve both the engaged PAs and the linked process elements. There 
must always be PAs involved in all GOPs. If a GOP is described without its PAs, then its representation is deficient. Similarly, a GOP is deficient if it does not involve process elements.

The next ontological question concerns the controversial issue of the possible randomness of GOPs. Many, if not most, researchers in the organization sciences "act as if" they are firmly convinced that GOPs are random or, at least, ought to be treated as such for the purpose of conducting publishable empirical research. Axiom 3 asserts this in the negative:

\section{Axiom 3. A GOP is not random.}

A GOP may appear to be random because its occurrence is not easily explainable to an observer or even to its members. That does not make it random. The assumption of randomness is a mathematical convenience that either masks a lack of understanding or is an attempt to change the research subject. It is also unnecessary by Axiom 1, because a GOP always involves those who are performing it. Actions occur and they are done by Processual Agents. The occurrence of a GOP can be triggered by an external event, which may be labeled as being random to a group, such as a "wildcat" strike, an interruption in electrical power, a computer malfunction, an accident to a key person, etc. Axiom 3 only states that the GOP itself is not random. The GOP, as a response, may involve learning, mistakes, etc., but still the people involved are doing specific things. Decisions are made, actions taken, and results are evaluated. Coping, floundering, and learning are considered purposive but not random. Axiom 3 sends a clear message that the common practice of encapsulating processes as variables and then treating them analytically as if they are random, when they are not, is at least unnecessary and probably inappropriate for the study of GOPs. This practice complicates and obscures GOPs.

An event is that which initiates a GOP. Events may include decisions that set a GOP into motion. Events include the completion of a GOP that precedes another. Events can be external to an organization, such as a natural disaster, the granting of a patent, the failure of an opponent, a signal from a computer to initiate a response, etc. These external events are relevant if they are linked to a GOP. A GOP begins with an event which is summarized by GOP Property 2 :

GOP Property 2. A GOP is activated by an event.

Argument: This property follows directly from the definition of an event and Axiom 3.

Although analytically trivial, this property is important to analyses of GOPs because it directs one's attention to ascertaining what events are relevant. That is why it is stated prominently as a GOP property. The point is that a GOP does not happen spontaneously or by magic. A GOP is not random. It is activated by an event.

The next ontological issue is whether or not a GOP must be linked to at least one other GOP. That is, can a GOP appear out of nowhere, with no antecedent, with no consequences? Can a GOP be an "orphan"? The answer in Axiom 4 is in the negative:

Axiom 4. A GOP is linked to at least one other GOP.

Axiom 4 directs one's attention to possible antecedent or subsequent GOPs.

\subsection{GOP Resources and Their Characteristics-In-Use}

Another obvious property of a GOP is that it involves resources, called GOP resources. These GOP resources are richer than those implied by the vague word "inputs." GOP resources include the knowledge required, information needed by the Processual Agent, the involved technological and support resources, plus the money and materials available and used in its performance. GOP resources are intrinsic to its performance within a unit, group, or organization. Moreover, there are process resources that cut across units, their boundaries, and time, as in the case of virtual-like organizational arrangements (Mackenzie, 1986b, 2001a), 24/7 operations, and common systems such as those for financial control, administration of HR policies, quality assurance, etc. The concept of GOP resources and their characteristics-in-use has evolved (cf. Mackenzie 1986a, 1991, 2000a, 2004a). The listing of known GOP resources and their characteristics-in-use continues to grow and change with new experiences. However, the best source for understanding their presence is in the 1986a work.

Now that the concept of GOP resources and their characteristics-in-use has been introduced, it becomes the basis for the fifth ontological GOP axiom.

Axiom 5. A GOP requires process resources and involves their characteristics-in-use.

Axiom 5 serves to "ground" a GOP to its place. If the GOP were random and did not involve process resources and their characteristics-in-use, one would not need to consider its place (cf. Malpas, 1999; Mackenzie \& Barnes, 2007). The GOP resources and their characteristics-in-use help define the context by providing information about 
how such GOPs are coordinated and who and what is involved in executing them.

These lists of GOP resources and their characteristics-in-use grew out of direct organizational design consulting experiences. In creating organizational logics for clients, problems arose about what processes to include and how and when to separate and combine various task processes. For example, if a bank has branches, then the teller tasks in different bank branches are separated because they are in different locations. If the tasks involve different technologies, they are separated analytically because the specific descriptions of the processes are different even if they share the same label. Each of the items in the GOP resources and in the characteristics-in-use emerged from such considerations. We are now in a position to state the next important feature of a GOP: its components.

GOP Property 3. A GOP has five components:

(1) The Processual Agents involved in the GOP;

(2) The steps or considerations contained in the GOP;

(3) The pairwise linkages between elements of the preceding steps or considerations;

(4) The outcomes of the GOP; and

(5) The GOP resources and their characteristics-in-use.

Argument: The first component follows from Axiom 1, the second by Axiom 2, the third by Axioms 2, 3, and 4, the fourth by Axioms 3 and 4, and the fifth by Axiom 5 .

The achievement of true in-commonness requires engaged management in order to create a congruency or fit among components 2,3, and 4; the GOP resources and their characteristics-in-use (component 5); and position interdependence (component 1). Each GOP has its own interdependencies as defined by its six components.

The GOP graph, F, shows all pairwise relationships among the sets of considerations and outcomes. A GOP graph is represented as a network or graph, $\mathbf{F}$, where $\mathbf{F}$ is the structure of the linked considerations and the outcomes. A GOP framework includes components 2-5 of a GOP. GOP frameworks can be generically represented by: $\mathbf{Y}=\mathbf{F}(\mathbf{C})$, where $\mathbf{C}$ is the set of considerations (component 2), $\mathbf{F}$ is the network or graph of the considerations and the linking of considerations to the outcomes, $\mathbf{Y}$ (component 3), and $\mathbf{Y}$ is the set of outcomes (component 4). The definition of a GOP framework allows the statement of another important feature of a GOP.

GOP Property 4. Every GOP has a process framework.

Argument: By GOP property 3, a GOP has five components, including the four (2-5) that define a GOP framework. Therefore, every GOP has a process framework.

This leads us to another ontological GOP property: it is discrete and not continuous. A GOP is said to be discrete if it has a beginning and an end, the links between its elements are defined, and the values of considerations and results are integers. This is summarized in GOP Property 5.

GOP Property 5. A GOP is discrete.

Argument: If a GOP is discrete, it has a beginning and an end, and the links between process elements are defined. By GOP Property 2, a GOP has a beginning activated by an event. By GOP Property 1, a GOP involves one or more PAs and two or more process elements. By Axiom 2, these process elements are linked. Therefore, a GOP has defined links between its process elements. The last question is whether or not a GOP has an end. The concept of an end implies that there is an outcome produced by the GOP or that there is a link to another GOP by GOP Property 4. By definition, a GOP has a process framework, whose right-hand side contains outcomes or links to other processes. Therefore, it has an end.

GOP Property 5 could be restated as "A GOP is not continuous." The technique of representing GOPs by continuous functions or differential equations does not match these ontological GOP properties. However, GOPs can be transformed to incorporate a wide variety of mathematical functions (Mackenzie, 2006b, 2009). A GOP always has a beginning and an end. It need not be simple and can contain subprocesses, etc., but a GOP can be defined, described, and evaluated. A GOP is made up of distinct elements.

GOP Property 6. A path in a GOP framework is a Processual Agent.

Argument: A path in a GOP framework is a vector of considerations, C, by a PA leading to an outcome in Y. The right-hand side of a GOP graph, after the last cj $€ \mathrm{C}$ in the path, is an outcome, yi $\in \mathrm{Y}$. An outcome of a process is an event. An event activates a GOP by GOP Property 2. A Processual Agent is anything that can affect a GOP. Therefore, a path in a GOP framework is a Processual Agent. 
Thus, how one navigates through a process framework can itself act as if it is causal of subsequent actions. This is a well-known feature of cellular automata and complexity theory (cf. Wolfram, 1994).

A path in $\mathbf{F}$ consists of its linkages in $\mathbf{C}$ to its outcome in $\mathbf{Y}$. The path is a vector of linked considerations in a generalized function such as $\mathbf{Y}=\mathbf{F}(\mathbf{C})$. That is, given the path, the outcome in $\mathbf{Y}$ is defined. Every path can also be seen as a vector of the values of the considerations from the initial consideration, $c_{1}$, to $y_{i}$. This leads to GOP Property 7.

GOP Property 7. Equifinality is possible in GOP frameworks, in that there is often more than one possible path to reach any given outcome.

Argument: This is a consequence of the procedure for defining a process framework and is illustrated in the examples of answering a telephone in Mackenzie, 2012.

\subsection{GOP Levels}

Behavior and events at one level are known to affect and be affected by behavior and events at other levels. Multi-level phenomena are a growing area of investigation. Most organizational researchers would argue that group and organizational behavior is inherently multi-level, which includes both levels of management and levels of analysis (cf. Yammarino \& Dansereau, 2002, 2004, 2006; and Dansereau and Yammarino, 2003, 2005, 2007). For example, when there is a boss, there is a subordinate. If there is a greater task, such as marketing, then there is a smaller task, such as preparing ad copy, etc. Despite this acceptance, the means for studying multi-level phenomena are not as advanced as they need to be. The notion of level is intuitive, but it has two very different meanings.

There are two broad classes of GOP levels. These are (1) inclusional, and (2) causal. The inclusional class of levels compares a pair of levels, $\mathrm{L}_{1}$ and $\mathrm{L}_{2}$, according to which one of them is a proper subset of, or included in, the other. The dimension of the inclusional objects must be the same for $\mathrm{L}_{1}$ and $\mathrm{L}_{2}$; otherwise there is no strict inclusion (e.g., a bushel of apples contains apples but not oranges). There are three basic types of inclusional classes of levels. These are (1) structural inclusion, in which one position is higher than the other, provided that (a) there is a direct link from the higher to the lower or an indirect link via a defined hierarchy, and (b) the GOP of the higher includes those of the lower; (2) levels of task aggregation; and (3) levels of interdependence (cf. Mackenzie 2001b, 2004c).

The causal class of levels compares a pair of levels, $\mathrm{L}_{1}$ and $\mathrm{L}_{2}$, according to the assignment of one as the cause of the other. If $\mathrm{L}_{1}$ is deemed to be the cause of $\mathrm{L}_{2}$, then there is an assumed existence of a transformation or function, $\mathrm{f}$, such that: $\mathrm{L}_{1} \rightarrow \mathrm{L}_{2}$. A construct or conclusion that is used to derive another construct or more general conclusion is said to be lower than that which it helps to derive. It is lower in the sense that it is underlying.

Types of causal levels include (1) simple functions: $y=f(x)$, where $x$ is the assumed the lower level "independent" variable, and y is the higher level "dependent" variable; (2) levels of derivation; (3) task process levels in the double hierarchy of tasks as shown in organizational logics; (4) implicit/explicit phenomena; and (5) nested GOP frameworks. Sometimes explicit phenomena are deemed to be caused by underlying implicit phenomena. Whenever this is the case, the explicit phenomena are considered to be a level above their implicit origins. An example of implicit and explicit phenomena comes from optics: white light is explicit and its spectrum (many constituent frequencies) is implicit.

The multi-level nature of GOPs is stated as the final ontological GOP axiom:

\section{Axiom 6. A GOP has more than one level.}

The argument for Axiom 6 depends on the concept of a GOP level. Given that, by Axiom 4, a GOP is linked to at least one other GOP, this link is often by adjacent levels. Furthermore, any GOP has its context and content due to its GOP resources and their characteristics-in-use. As there can be levels of aggregation for each GOP, there are multiple inclusional levels. Similarly, as there are hierarchical levels of those involved in these levels, there is another source of multiple inclusional levels, etc. There can also be different causal levels as well. For example, one can have multiple inclusional levels due to the task process levels. In fact, it is difficult even to conceive of a GOP that does not involve more than a single level, whether by inclusion or cause.

\subsection{Loops in GOPs?}

The general notion of loops in the description of GOPs is a popular metaphor which is often intuitively understandable. In this aspect of the argument, process frameworks will be seen as immediately controversial because loops are considered unnecessary.

Consider the task processes of the "front-end" or check-out department of a large retail store. On the "line" are 
employees whose job is to check-out the purchases of a continuing stream of customers. Their duties are varied and contingent. They greet customers, scan the products, handle discounts and coupons, look up prices of sale items, make change, conduct credit transactions, and help "bag" the purchases. At any time this flow of activities can be interrupted by minor crises. The supervisors behind the checkers perform the duties of directing, controlling, and coordinating the activities of the checkers. They deal with training, managing the flow of customers, negotiating work schedules, handling front-end problems such as equipment malfunction, unruly customers, ensuring security, preventing fraud and stealing, and generally overseeing the activities of the front-end personnel. In addition, there are also planning processes which are performed by the supervisor's supervisor or Front-End Manager. The planning issues involve determining the right equipment, preparing for a special sale, calculating manpower requirements, working with shift managers, coordinating to ensure proper training, etc.

The organizational logic of the front-end operation would include a bundle of planning tasks (P), more bundles for directing, coordinating, and controlling tasks (DCC), and many bundles of execution tasks (E). A schematic organizational logic diagram would look like $\mathbf{P} \rightarrow \mathbf{D C C} \rightarrow \mathbf{E}$. It should be clear that not all of these tasks are on-going at the same rate, and that "feedback loops" are unnecessary as they are built into the descriptions of the $\mathbf{E}, \mathbf{D C C}$, and $\mathbf{P}$ tasks. In fact, many of the tasks can run independently of the others for significant periods of time. Checking out customers might resemble a loop within an $\mathbf{E}$ process because checkers do a similar task over and over again. However, they perform it for different customers with different purchases as they are served. The fact that $\mathbf{P}$ tasks lead to DCC tasks and these to $\mathbf{E}$ tasks does not mean that those performing the $\mathbf{E}$ tasks (front-end check-out personnel) are continually supervised. Depending on their training, proficiency, and the quality of the equipment, the more competent and experienced are mostly autonomous in terms of direct and continued supervision. It also does not mean that every $\mathbf{P}$ task automatically returns to the subsequent $\mathbf{D C C}$ and $\mathbf{E}$ tasks because $\mathbf{P}$ tasks are rarely concurrent with DCC tasks and DCC tasks are often not concurrent with $\mathbf{E}$ tasks. The task and personnel linkages are neither impersonal nor abstract. The main point is that it is not necessary to invoke "loops" in the performance of GOPs.

We now return to the formal discussion. Directly linked GOPs, $\mathbf{P}_{\mathrm{i}}$ and $\mathbf{P}_{\mathrm{j}}$, are said to be in parallel if one is not the predecessor of the other. This leads to another important property of GOPs.

GOP Property 8: For any pair of GOPs, $\mathbf{P}_{\mathrm{i}}$ and $\mathbf{P}_{\mathrm{j}}$, there are exactly three defined

link relationships: (a) $\mathbf{P}_{\mathrm{i}} \rightarrow \mathbf{P}_{\mathrm{j}}$, (b) $\mathbf{P}_{\mathrm{j}} \rightarrow \mathbf{P}_{\mathrm{i}}$, and (c) $\mathbf{P}_{\mathrm{i}}$ and $\mathbf{P}_{\mathrm{j}}$ are in parallel.

Argument: This is obvious from the structure of the graph. If $\mathbf{P}_{\mathrm{i}}$ and $\mathbf{P}_{\mathrm{j}}$ are in a chain of length greater than one, they do not have a direct link relationship.

GOP Property 9: For any GOP there exists a prime common predecessor.

Argument: By Axiom 4, the GOP is linked to at least one other GOP. If this GOP is in parallel, it is not a predecessor but it is also not linked. If it is a successor, it cannot be a predecessor by GOP Property 8 . If it is a predecessor, it is in-common if there is a chain from it to the GOP. Can there be more than one common predecessor? Sure, but then that one would also be a predecessor of the other, or vice versa. By GOP Property 8 , one of them must be the predecessor of the other. If one continues this argument back through all of the sets of possible predecessors, one arrives at one for which there is not a common predecessor. This survivor is the prime common predecessor.

An issue related to the linking issues between GOPs is the notion of a loop. Loops are popular in electrical engineering models of circuits, in systems theory, and everywhere else the metaphor of positive and negative feedback is deployed to make what is said seem more scientific. The technicism, "feedback loop," is often a vague metaphor. But are "loops" either necessary or sufficient to describe GOPs?

A loop between a pair of GOPs means that one is both the predecessor and the successor of the other. A loop between $\mathbf{P}_{\mathrm{i}}$ and $\mathbf{P}_{\mathrm{j}}$ looks like: $\mathbf{P}_{\mathrm{i}} \leftrightarrow \mathbf{P}_{\mathrm{j}}$. Please note that such a loop can be indirect when there are other GOPs in between $\mathbf{P}_{\mathrm{j}}$ and $\mathbf{P}_{\mathrm{i}}$.

GOP Property 10: A GOP does not contain loops.

Argument: Loops violate GOP Property 8. There is no loop if $\mathbf{P}_{\mathrm{i}}$ and $\mathbf{P}_{\mathrm{j}}$ are in parallel and no loop if $\mathbf{P}_{\mathrm{i}} \rightarrow \mathbf{P}_{\mathrm{j}}$ or $\mathbf{P}_{\mathrm{j}}$ $\rightarrow \mathbf{P}_{\mathrm{i}}$. By GOP Property 8 , there are three link relationships, $\mathbf{P}_{\mathrm{i}} \rightarrow \mathbf{P}_{\mathrm{j}}, \mathbf{P}_{\mathrm{j}}$

$\rightarrow \mathbf{P}_{\mathrm{i}}$, and $\mathbf{P}_{\mathrm{i}}$ and $\mathbf{P}_{\mathrm{j}}$ are in parallel. This argument can be extended to chains of length $\mathrm{k}(\mathrm{k} \geq 1)$.

But if both $\mathbf{P}_{\mathrm{i}} \rightarrow \mathbf{P}_{\mathrm{j}}$ and $\mathbf{P}_{\mathrm{j}} \rightarrow \mathbf{P}_{\mathrm{i}}$ are in a chain of length k, then eventually this creates a contradiction because, by Property 8, either $\mathbf{P}_{\mathrm{i}} \rightarrow \mathbf{P}_{\mathrm{j}}$ or $\mathbf{P}_{\mathrm{i}} \rightarrow \mathbf{P}_{\mathrm{j}}$. 
GOP Property 11: A consideration can only occur once in a path in a process framework.

Argument: If a consideration occurs more than once, it creates a loop. This is not possible by GOP Property 10 .

Of course, a consideration can occur in more than one path in a process framework. Real people, as opposed to electrons, are not automatons. Engaged Processual Agents in a GOP will usually change a process if it does not work to their satisfaction. The idea that a normal (not obsessive or autistic) PA would endlessly engage in unlimited looping by repeating a defective process ad infinitum makes no sense. However, it makes sense for an electron. The fact that an outcome of a process is to redo it is not a loop but rather an event leading to performing the process again, but probably using a different path through the same process framework. Repeated failures may result in redesigning the GOP.

Of course, one can always draw a process diagram with a loop. A backward arrow to a predecessor makes it appear as if it is a loop. But this "loop" only signifies that the process is affected by an event that requires it to return to a predecessor for an update, correction, or repetition. The "loop" creating the link to a predecessor is shorthand for repeating a process. A question arises about the number of such repetitions allowed by "mostly sane" humans before they begin to "catch on" and revise the GOP. GOP Property 10 suggests that they lose patience quickly.

\subsection{Encapsulating GOPs}

The encapsulation of a GOP involves converting it into a variable, which usually results in confusion. The specific case of GOP Property 12 is especially important and is thus highlighted.

GOP Property 12. A measure of a GOP is not the GOP.

Argument: Let $\mathbf{P}$ denote a GOP and $\mathrm{m}(\mathbf{P})$ a measure or attribute defined on $\mathbf{P}$. $\mathbf{P}$ is a process and $\mathbf{m}(\mathbf{P})$ is a number, so it is impossible to equate $\mathbf{P}$ and one of its attributes $\mathbf{m}(\mathbf{P})$. Furthermore, an attribute of a GOP is not the GOP itself.

Variance models require the conversion of a process into a measure (e.g., a group structure into a measure of structural centrality), but the measure of structural centrality is not the same as its structure. Structural centrality is a number, and the structure is a pattern of interactions or relationships. Different structures may have the same index of centrality. A GOP involves considerations and its results are outcomes. A measure of an outcome is not the same as the steps or considerations in the GOP itself which may lead up to it. In many ways, attempts to encapsulate a process into a scalar are attempts to change the subject away from a GOP to a computational routine, away from that which requires observation and engagement, and toward that which is analytically available and convenient.

\subsection{Place and the Breath of Life}

An additional desiderata is that a GOP representation incorporates its place. Place is not just a location. It is a metaphysical concept. The philosopher Malpas (1999), in a personal communication, gave this definition of place: "Place is an overarching frame that encompasses the subject that acts, the object towards which action is directed, and the environmental context of action" (cited in Mackenzie and Barnes, 2007, p. 94). A group or an organization creates places for its members. While not all members will have the same place, they still share a common content and context for their behaviors. What they do occurs in context provided by the group or organization. The content of their actions, and even the employed technologies, occur within the context of the group or organization. The concept of a place is personal but is inherently processual by nature, and it adds to the sense of the "breath of life" of a GOP. Place is not and cannot be merely a variable. There is a new GOP property: A GOP is enplaced, which is restated as GOP Property 13:

GOP Property 13: A GOP has its place.

Argument: By definition of place, it encompasses the subject that acts, the object toward which action is taken, and the environmental context of action. By Axiom 1, a GOP involves one or more processual agents. By Axiom 2, it involves two or more linked elements, and by Axiom 5, it requires process resources and their characteristics-in-use. These process resources and their characteristics-in-use incorporate some contextual and content aspects of the GOP. In addition, in terms of a GOP context of action, by GOP Property 2, it is activated by an event; by Axiom 4, it is linked to at least one other GOP; and by Axiom 6, it has more than one level.

It is difficult to comprehend a GOP without understanding something about its place. For example, Mackenzie and Barnes (2007) argue that nine leadership approaches lack incorporation of place, which creates problems in making applications and testing approaches to understanding the complex phenomena of leadership. By GOP Property 13, every GOP has its place. A GOP is not a mere abstraction. It is something that happens within a 
place. It involves people doing things within it. The place of a GOP incorporates its context and content. The GOP resources and their characteristics-in-use incorporate the context. The description of the GOP considerations incorporates its content. And, as we learned from GOP Property 12, a measure of a GOP is not the same as a GOP. But what is also interesting is that a representation of a GOP is not the same as a GOP, because of the criterion that it must be realizable. A GOP representation is often less realized than the actual GOP.

One feature of the discussion of GOPs in the organization sciences is the variety and diversity of possible representations. There is a wide gulf between the least actualized (a grand metaphor such as life cycles) and the fully actualized. A GOP is said to be fully actualized in its actual operating arrangements of a working group or organization. GOPs can be described at different levels of the actuality of the target GOP.

A GOP is said to be represented if it has an enplaced process framework. This brings us to the next GOP property:

GOP Property 14. A representation of a GOP incorporates: (a) its engaged Processual Agents; (b) its linked elements; (c) its linkages to other GOPs; (d) its process resources and their characteristics-in-use; and (e) an ability to incorporate more than one level.

Argument: This follows directly from the definition of the representation of a GOP, and part (a) from Axiom 1; part (b) from Axiom 2; part (c) from Axiom 4; part (d) from Axiom 5; and part e) from Axiom 6.

Hence, by Axiom 5 and the definition of a GOP representation, a representation of a GOP incorporates its process resources and their characteristics-in-use. Please note that GOP Property 14 does not imply that every aspect of GOP resources and their characteristics-in-use needs to be incorporated. The representation need not be fully actualized. GOP Property 14 means that they can be incorporated. However, it is not a GOP representation unless and until at least some of the GOP's resources and their characteristics-in-use are actually incorporated into the description of the GOP.

\section{The Process Framework Is a Working Common GOP Representation}

\subsection{The Feasibility of Process Frameworks as A Common GOP Representation}

The process framework, $\mathbf{Y}=\mathbf{F}(\mathbf{C})$, is a feasible GOP representation if it satisfies five criteria. The primary criterion is the incorporation of the breath of life. The process framework meets this criteria because it incorporates Processual Agents and the subject matter of groups and organizations. It is also enplaced. It offers an algebraic structure to the representation of GOPs, and this algebraic structure also works for specified classes of multi-level GOPs, so the process framework meets the second and third criteria. The process framework is realized by GOP Property 14. Finally, as has been demonstrated in numerous studies, a proposed process framework can be rejected as defective or deficient. In fact, a researcher using the process framework for a study is advised actively and deliberately to seek to uncover problems and counterexamples in the GOP framework. The process of finding these problems, followed by efforts to "fix" them, usually results in improvements. Proactively seeking problems with one's GOPs usually saves time by avoiding wasting efforts on flawed formulations. Clearly, the process framework is a feasible GOP representation.

The next question is whether or not it is a common GOP representation. It has been used in a wide variety of studies ranging from the process of becoming hostile to organizational design. The result of process frameworks being applicable in a fairly wide spectrum of possible GOPs at least makes a case for it to be considered a common GOP representation. But, given the much larger domains of GOPs that have not been analyzed by process frameworks, it is simply premature to claim process frameworks as a common GOP representation. For now, consider process frameworks as a working common GOP representation.

\subsection{Process Frameworks and the Ten Desiderata}

The next step in ascending from feasible to common is to examine a feasible GOP representation against the ten desiderata. Its definitions and axioms are articulated (D1); it provides an analytical framework (D2); it has the capacity to incorporate actual data (D3); and it can be used for multi-purposes (D4). Clearly, a process framework satisfies these desiderata.

The fifth desideratum states that the limitations of a GOP representation need to be defined. It is, at this time, unclear that process frameworks fully meet this test. There are limitations to process frameworks as the common representation of GOPs because they have only been applied to the author's own research and that of some of his students. There are other GOPs for which process frameworks has not been applied. Furthermore, this representation may prove cumbersome in process research whose subject does not match the criterion of realizability. Examples include studies of sensemaking, organizational identity, and narrative research. 
By its very ontological axioms, process frameworks are invalid for the type of process models used in machine learning with continuous data, learning with probabilistic representation, data mining, extracting dynamic models from imperfect data, etc. While these are not GOP processes per se, they serve to point out that the process framework is rooted in six ontological axioms. Differential equation dynamic models with continuous data violate at least five of the six axioms. There are processes that are not GOPs, and different methods have evolved to handle them. Care needs to be taken in appropriating a process modeling tool from one context and then, by analogy, applying it mechanically to actual GOPs. Similarly, applying a GOP process representation to non-GOPs may be a mistake.

The sixth desideratum (D6) is that a common GOP representation should provide procedures for connecting it with other GOPs as required. This is built into the very definition of a process framework. Process frameworks differentiate between the actual GOP representation and postulated measures of outcomes (D7) as shown in GOP Property 12. The process framework is testable (D8). Process frameworks have face validity (D9). And it is possible to conclude, based on many studies and applications, that it may contribute to the improvement of GOP science.

\subsection{Other Properties of Process Frameworks}

Lundberg and Young (2005, p. 5) point out that many of the arguments about theory and method in the organization sciences involve disputes about oversimplified "dichotomies as those between quantitative and qualitative methods..., micro and macro levels of analysis, and various research purposes such as description and prediction...". They argue for the usefulness of combining multiple approaches (e.g., paradigms, methods, and research strategies). They further argue for the possibility (and even the desirability) of integrating positivist and interpretative approaches. They also point out that "the tensions engaged by these debates are, in fact, functional...".

It turns out that the properties of process frameworks, when applied with some open-mindedness, discipline, and creativity, can accomplish what Lundberg and Young (2005) prescribe for the organization sciences. In addition to their 14 GOP properties, there are other features of process frameworks that are organized by the components of a process framework, the set of considerations, $\mathbf{C}$, the process graph, $\mathbf{F}$, and the outcomes, $\mathbf{Y}$ (cf. Mackenzie 2000a, 2004a).

In this analysis, it is clear that process framework graphs can be either quantitative or qualitative. In fact, even qualitative GOPs can be enhanced into quantitative models (cf. Mackenzie 2006b, 2009). Process frameworks can be used for both micro and macro levels of analysis. For some GOPs, one can also show how the "macro" links eventually to the "micro," and vice-versa. Process frameworks have been used to describe, explain, and predict group and organizational behavior. In fact, creating a process framework makes it easier to describe and compare group and organizational behavior. The description forms a basis for explaining the phenomena of interest, and the explanation can be tested and used for making predictions. The flexibility of the choice of considerations $\mathbf{C}$, the GOP graph, $\mathbf{F}$, and the outcomes, $\mathbf{Y}$, allows for inclusion of multiple paradigms, methods, and research strategies. Process frameworks are not limited to positivistic approaches. They certainly can include interpretative analyses. The effort to understand, then describe, then construct, and finally test, a process framework embodies the creative tensions of reconciling and integrating disparate paradigms, methods, and research strategies. They certainly involve tensions and complexities of bridging the theoretical with the actual GOP behavior. A detailed description of the properties of process frameworks can be found in Mackenzie (2000a).

A recent line of inquiry uses the properties of process frameworks to provide a technology and a class of criteria for evaluating the rigor of multi-level research. This includes Mackenzie (2004b and 2006b). Multi-level research rests on the interdependent choices of selecting the phenomena to be studied, the definition of the relevant levels, the procedures for assigning levels, and the rules (functions) for relating one level to another. Process frameworks, by Axiom 6, are always to be considered multi-level. Multi-level research always involves either causal or inclusional levels and it sometimes includes both.

\section{Summary and Conclusions}

Mackenzie (2012) argued for the value of having a common definition of group and organizational processes and the means for representing them. A candidate GOP representation must meet five tests for it to be feasible. If it is feasible, then apply the ten proposed desiderata. If a proposed GOP representation satisfies them, it would be a common GOP representation.

Four candidate GOP representations are introduced and evaluated. These include the MIT process handbook of 
Malone, et al, 2003, the knowledge representation models of Sowa (2000), the dynamic process simulation work by Melcher (2012), and process frameworks (Mackenzie, 2000a, 2004a).

The most developed is the MIT process handbook. It exemplifies how researchers, by combining theory, engineering, tools, and applications, can make demonstrable progress. The main problems with this approach are the self-limiting nature of the choice of GOP processes, problems with its concept of processes, and the deficiencies and defects in its concept of coordination. The MIT process handbook is probably feasible but it is not yet a working common GOP representation.

The knowledge engineering concepts and models included in Sowa's 2000 textbook provide many useful tools that could enhance the development of the science of group and organizational processes. It is a book of tools developed by the AI community and related research to provide concepts and methods for modeling representations of knowledge. This book is not intended to be a book on group and organizational processes. It does not propose a feasible candidate representation of GOPs, but that was never its purpose. It does offer a compendium of valuable guides to some powerful methods that, when combined with humans, offer promise that can yield progress in the science of group and organizational processes.

The dynamic systems work by Melcher (2012) introduces a long-term, principled effort to develop and establish a means for engineering tools and concepts in dynamic systems simulation to study specified GOPs. While it is not a common GOP representation, Melcher's work opens up and engineers methods to analyze the dynamics of certain group and organizational processes.

The fourth candidate GOP representation examined is that of Mackenzie (2000a, 2004a). This work asserts that those involved are engaged Processual Agents. This process framework approach is summarized by: $\mathbf{Y}=\mathbf{F}(\mathbf{C})$, where $\mathbf{C}$ is the set of steps or considerations in a process, $\mathbf{Y}$ is the set of possible outcomes, and $\mathbf{F}$ is the network which connects the considerations to each other and to the outcomes. The equation $\mathbf{Y}=\mathbf{F}(\mathbf{C})$ is derived using six ontological axioms:

A1. A GOP involves one or more Processual Agents.

A2. A GOP involves two or more linked process elements.

A3. A GOP is not random.

A4. A GOP is linked to at least one other GOP.

A5. A GOP representation requires process resources and involves their characteristics-in-use.

A6. A GOP has more than one level.

Fourteen GOP properties are derived to demonstrate some of the features of process frameworks.

The process framework is a feasible GOP representation in that it seems to meet the ten desiderata but its limitations are not yet fully understood. That is why it is called a working common GOP representation.

The likelihood that process frameworks are the final answer to having a common GOP representation is unknown. Many will not fully accept the five feasibility criteria and the ten desiderata. That they are made explicit should promote the discussion and revisions leading to an improved science of groups and organizations. Those who disagree are invited to offer their own axioms and definitions and use them to derive their rival GOP representations. Then one can compare, contrast, and eventually synthesize, improving concepts of GOPs and their representation.

\section{Acknowledgements}

Numerous people have added support and commentary that helped improve this article. Craig C. Lundberg (NT) helped reconcile the text with the extant literatures; Arlyn Melcher gave his time and advice for helping the author comprehend his research; Donald F. Utter for guiding the use of philosophy; and Susan M. Treber for her insightful copy editing.

\section{References}

Acar, W., Melcher, A. J., \& Apperle, K. E. (1989). The implementation of innovative strategies. International Journal of Technology Management, 4(6), 631-651.

Barnes, F. B. (1996). The Baldrige Criteria: A Quality Improvement Journey without a Map. Unpublished doctoral dissertation, School of Business, University of Kansas, Lawrence, KS.

Boudreau, M. C., \& Rubey, D. (1999). Organizational transition to enterprise resource planning systems: Theoretical choices for process research. In Proceedings of the $20^{\text {th }}$ International Conference on 
Information Systems (1015-1099) (pp. 219-299). Charlotte, NC.

Crowston, K. (2003). Process as theory in information systems research. In T. W. Malone, K. Crowston, \& G. A. Herman (Eds.). Organizing Business Knowledge: The MIT Process Handbook. Cambridge, MA: The MIT Press, $177-190$.

Daft, R. L. (2000). Management (5th ed.). Fort Worth, TX: The Dryden Press.

Dansereau, F., \& Yammarino, F. J. (Eds.) (2007). Research in Multi-level Issues: Multi-level Issues in Organizations and Time (Vol. 6). Elsevier Science, Oxford, UK.

Dansereau, F., \& Yammarino, F. J. (Eds.) (2003). Research in Multi-level Issues: Multi-level Issues in Organizational Behavior (Vol. 2). Oxford, UK: Elsevier Science.

Dansereau, F., \& Yammarino, F. J. (Eds.) (2005). Research in Multi-level Issues: Multi-level Issues in Social Systems. Vol. 4, Oxford, UK: Elsevier Science.

Dreyfus, H. L. (1993). What Computers Still Can't Do: A Critique of Artificial Reason. Cambridge, MA: The MIT Press

Giola, D. A., \& Chittipeddi, K. (1991). Sensemaking and sensegiving in strategic change. Strategic Management, 12, 433-448. http://dx.doi.org/10.1002/smj.4250120604

Giola, D. A., Schultz, M., \& Corley, K. G. (2000). Organizational identity, image, and instability. Academy Management Review, 25(1), 63-81.

Hall, R. I. (1976). A system pathology of an organization: The rise and fall of the old Saturday Evening Post. Administrative Science Quarterly, 21(June), 185-211. http://dx.doi.org/10.2307/2392042

Hall, R. I. (1984). The natural logic of management policy making: Its implications for the survival of an organization. Management Science, 30(8), 905-927. http://dx.doi.org/10.1287/mnsc.30.8.905

Lippitt, M., \& Mackenzie, K. D. (1976). Authority-task problems. Administrative Science Quarterly, 21(4), 643660. http://dx.doi.org/10.2307/2391721

Lundberg, C. C., \& Young, C. A. (2005). Foundations of inquiry: Choices for tradeoffs in the organization sciences. Stanford, CA: Stanford Business Books.

Mackenzie, K. D. (2000a). Processes and their frameworks. Management science, 46(1), 110-125. http://dx.doi.org/10.1287/mnsc.46.1.110.15126

Mackenzie, K. D. (1976a). A theory of group structures, Volume I: Basic theory. New York: Gordon and Breach Science Publishers, Inc.

Mackenzie, K. D. (1976b). A theory of group structures, Volume II: Empirical tests. New York: Gordon and Breach Science Publishers, Inc.

Mackenzie, K. D. (1986a). Organizational design: The organizational audit and analysis technology. Norwood, NJ: Ablex Publishing Corporation.

Mackenzie, K. D. (1986b). Virtual positions and power. Management Science, 32(5), 622-642.

Mackenzie, K. D. (1991). The Organizational Hologram: The Effective Management of Organizational Change. Boston, MA: Kluwer Academic Publishers. http://dx.doi.org/10.1007/978-94-011-3917-5

Mackenzie, K. D. (1994). The science of an organization, part I: A new model of organizational learning. Human Systems Management, 13(4), 249-258.

Mackenzie, K. D. (1997a). Organizational work, part I: The theory. Human Systems Management, 16(1), 9-26.

Mackenzie, K. D. (1997b). Organizational work, part II: The distribution of work. Human Systems Management, 16(2), 99-115.

Mackenzie, K. D. (1998a). A framework for managing risky situations. International Journal of Organizational Analysis, 6(1), 5-31.

Mackenzie, K. D. (1998b). The prime directive for organizations. International Journal of Organizational Analysis, 6(4), 289-309.

Mackenzie, K. D. (2000b). Knobby analyses of knobless survey items, part I: The approach. International Journal of Organizational Analysis, 8(2), 131-154.

Mackenzie, K. D. (2000c). Knobby analyses of knobless survey items, part II: An application. International 
Journal of Organizational Analysis, 8(3), 239-262.

Mackenzie, K. D. (2000d). Virtual positions, processes, and organizations. In the Government and NGO (pp. 383-403). Seoul, Korea: KAPA, INC.

Mackenzie, K. D. (2001a). Virtual-Like Organizational Arrangements and NGOs. In M. A. Rahim, R. T. Golembiewski, \& K. D. Mackenzie (Eds.), Current Topics in Management (Vol. 6, pp. 265-287). Stamford, CT: JAI Press.

Mackenzie, K. D. (2001b). The organization of organizations. International Journal of Organizational Analysis, 9(2), 116-148. http://dx.doi.org/10.1108/eb028930

Mackenzie, K. D. (2004a). The process approach to multi-level organizational behavior. In F. J. Yammarino, \& F. Dansereau (Eds.), Research in Multi-Level Issues, Vol. 3: Multi-Level Issues in Organizational Behavior and Processes (pp. 347-417). Oxford, UK: Elsevier Science.

Mackenzie, K. D. (2004b). Making strange knowledge more intelligible. In F. J. Yammarino, \& F. Dansereau (eds.), Research in Multi-Level Issues, Vol. 3: Multi-Level Issues in Organizational Behavior and Processes (pp. 435-441). Oxford, UK: Elsevier Science.

Mackenzie, K. D. (2004c). The levels of levels in organizational phenomena. In M. A. Rahim, R. T. Golembiewski, \& K. D. Mackenzie (Eds.), Current Topics in Management (Vol. 9, pp. 225-255). New Brunswick, NJ: Transactions Publishers.

Mackenzie, K. D. (2006a). The LAMPE theory of organizational leadership. In F. J. Yammarino, \& F. Dansereau (Eds.), Research in Multi-Level Issues, Vol. 5: Multi-Level Issues in Social Systems (pp. 345-428). Oxford, UK: Elsevier Science.

Mackenzie, K. D. (2006b). Some ideas about testing processual theories. In F. J. Yammarino, \& F. Dansereau (eds.), Research in Multi-Level Issues, Vol. 5: Multi-Level Issues in Social Systems (pp. 443-475). Oxford, UK: Elsevier Science.

Mackenzie, K. D. (2007). The god of variance has feet partly of iron and partly of baked clay. International Journal of Organizational Analysis, 15(1), 5-22. http://dx.doi.org/10.1108/19348830710860129

Mackenzie, K. D. (2009). Process skeletons and functions. Human Systems Management, 28(4), 201-212.

Mackenzie, K. D. (2010). Turf disputes within federal systems: Leadership amidst enforceable checks and balances. Leadership Quarterly, 21(6), 1050-1068. http://dx.doi.org/10.1016/j.leaqua.2010.10.008

Mackenzie, K. D. (2011). Practitioner's Guide for Organizing and Organization. Lawrence, KS: EMAC Assessments, LLC.

Mackenzie, K. D. (2012). The science of group and organizational processes. Engineering Management Research, 1(2), 133-145. http://dx.doi.org/10.5539/emr.v1n2p133

Mackenzie, K. D., \& Barnes, F. B. (2007). The unstated consensus in leadership approaches. International Journal of Organizational Analysis, 15(2), 92-118. http://dx.doi.org/10.1108/19348830710868266

Mackenzie, K. D., \& Bello, J. A. (1981). Leadership as a task process uncertainty control process. Human Systems Management, 2(3), 199-213.

Mackenzie, K. D., \& Benoit, C. A. (1997). Organizational work, part III: Empirical results. Human Systems Management, 16(2), 117-137.

Mackenzie, K. D., \& Pate, L. E. (2009). Effective leadership in virtual-like organizational arrangements. In T. Torres-Coronas, \& M. Arias-Olivia (Eds.), Encyclopedia of Human Resources Information Systems: Challenges in e-HRM (Chapter LXXVII, pp. 256-266). Hershey, PA: Information Science Reference.

Mackenzie, K. D., \& Rahim, M. A. (2003). Strong inference and weak data. In M. A. Rahim, R. T. Golembiewski, \& K. D. Mackenzie (Eds.), Current Topics in Management (Vol. 8, pp. 315-339). New Brunswick, NJ: Transactions Publishers.

Mackenzie, K. D., \& Scott, R. K. (2001). A pure virtual organization. In M. A. Rahim, R. T. Golembiewski, \& K. D. Mackenzie (Eds.), Current Topics in Management (Vol. 6, pp. 69-95). Stamford, CT: JAI Press.

Mackenzie, K. D., Golembiewski, R. T., \& Rahim, M. A. (2000). Evolving From Data Expertise to Expert Data. In M. A. Rahim, R. T. Golembiewski, \& K. D. Mackenzie (Eds.), Current Topics in Management (Vol. 5, pp. 355-366). Stamford, CT: JAI Press. 
Mackenzie, K. D., Shoemaker, T., \& Utter, D. F. (1994). Development of organizational design support systems. Journal of Organizational Computing, 3(4), 241-270. http://dx.doi.org/10.1080/10919399409540227

Maitlis, S., \& Lawrence, T. (2003). Orchestral maneuvers in the dark understanding failures in organizational $\begin{array}{lllll}\text { strategizing. } & \text { Journal of }\end{array}$ http://dx.doi.org/10.1111/1467-6486.t01-2-00006

Malone, T. W., \& Crowston, K. (1994). The interdisciplinary study of coordination. ACM Computing Surveys, 26(1), 87-119. http://dx.doi.org/10.1145/174666.174668

Malone, T. W., Crowston, K., \& Hermann, G. A. (Eds.) (2003). Organizing businessknowledge: The MIT process handbook. Cambridge, MA: MIT Press.

Malpas, J. E. (1999). Place and Experience: A Philosophical Inquiry. Cambridge, UK: Cambridge University Press. http://dx.doi.org/10.1017/CBO9780511487606

Marker, D. C. (2002). The Phenomena of Encroaching Processes: Towards a Theory of Organizational Change. Unpublished doctoral dissertation, School of Business, University of Kansas, Lawrence, KS.

Melcher, A. J. (1976). Organizational Structure and Process: A Systems Approach. New York: Prentice-Hall.

Melcher, A. J. (2012). Formulating a research question: Considerations and guidelines. Unpublished manuscript. Southern Illinois University at Carbondale.

Melcher, A. J., \& Melcher, B. (1980). Towards a system theory of policy analysis: Static versus dynamic analysis. Academy of Management Review, 5(2), 235-247.

Melcher, A. J., Khouja, M., \& Broth, D. (2002). Toward a productive classification system. Business Process Management Journal, 8(1), 53-79. http://dx.doi.org/10.1108/14637150210418638

Pentland, B. T. (1995). Grammatical models of organizational processes. Organization Science, 6(5), 541-556. http://dx.doi.org/10.1287/orsc.6.5.541

Pentland, B. T. (2003). Grammatical models of organizational processes. In T. W. Malone, K. Crowston, \& G. A. Hermann (Eds.), Organizing Business Knowledge: The MIT Process Handbook (pp. 191-214). Cambridge, MA: The MIT Press.

Polkinghorne, D. E. (1988). Narrative Knowing and the Human Sciences. Albany, NY: State University of New York Press.

Sowa, J. F. (2000). Knowledge representation: Logical, philosophical, and computational foundations. Pacific Grove, CA: Brooks/Cole.

Taylor, C. (1993). Engaged agency and background in Heidegger. In C. Guignon (Ed.), The Cambridge Companion to Heidegger (pp. 317-336). Cambridge, UK: The Cambridge University Press. http://dx.doi.org/10.1017/CCOL0521385709.013

Thompson, J. D. (1967). Organizations in Action: Social Science Bases of Administrative Theory. New York: McGraw-Hill.

Weick, K. (1969). The Social Psychology of Organizing. Reading, MA: Addison-Wesley.

Weick, K. (1995). Sensemaking in Organizations. Thousand Oaks, CA: Sage.

Whitehead, A. N. (1937). Analysis of meaning. In A. N. Whitehead, Essays in Science and Philosophy (pp. 122-131). New York: Philosophical Library.

Wolfram, S. (1994). Cellular Automata and Complexity: Collected Papers. Cambridge, MA: Perseus.

Wooldridge, M. J., \& Jennings, N. R. (1995). Intelligent agents, lecture notes in AI 890. New York: Springer-Verlag, 1ff. http://dx.doi.org/10.1007/3-540-58855-8

Yammarino, F. J., \& Dansereau, F. (Eds.) (2002). Research in Multi-level Issues: The Many Faces of Multi-level Issues (Vol. 1). Oxford, UK: Elsevier Science.

Yammarino, F. J., \& Dansereau, F. (Eds.) (2004). Research in Multi-level Issues: Multi-level Issues in Organizational Behavior and Processes (Vol. 3). Oxford, UK: Elsevier Science.

Yammarino, F. J., \& Dansereau, F. (Eds.) (2006). Research in Multi-level Issues: Multi-level Issues in Social Systems (Vol. 5). Oxford, UK: Elsevier Science. 